\begin{abstract}
This paper revisits core family support messages for social work practice in working with children and families linking to findings from high profile child protection cases in the UK and the Republic of Ireland. Drawing on a comparative study where these identified practice messages were explored through the lens of testimony of Family Support Workers in the UK and Ireland, these core messages are examined. Operating with hard to engage children and parents, we hear how families and Family Support Worker colleagues now view the core functions of child and family work across both jurisdictions (Ireland and England). The authors argue that by naming a more detailed set of practices that are deemed as most useful by families, based on the benefits and challenges of intensive family support work, key messages arise that have major resonance for social work and multi agency practice into the future. A basic message from this study is that valuable lessons on engagement and intervention with families can be drawn for professionals by examining the practice elements of this group of para professionals in the child and family arena. This paper adds to debates on the role support and intervention in social work and family support work.
\end{abstract}

Key Words: Family support, child welfare, comparative social work

\title{
Family Support in Practice: Voices from the field
}

\section{Introduction}

Since the early 1980s, the fundamentals of child and family social work such as the rationale for, role of, and success accruing from social worker interventions has been increasingly challenged by many, both within and outside of the profession. Even in the last five years alone, with notable high profile child protection case failures such as the Baby Peter case in the UK, and the Roscommon incest case in the Republic of Ireland, strong questioning regarding the efficacy of the social work profession has been the subject of major inquiries in both jurisdictions. In this light, it could also be argued that the earlier 
'refocussing' debate of the 1980s about re-directing interventions with children and families towards family supportive preventative interventions advocated for by many including Jack in the UK (1997) and Pinkerton and colleagues in Ireland (Canavan, Pinkerton \& Dolan, 2006) has been all but lost to the belief (regardless of its verification) that child \& family social work is in Irish and UK Contexts now really only about safeguarding children.

More recently however, this has again been rebutted by a call for social workers to hold the line on their family support functions (Frost \& Dolan, 2012); to return to more direct casework and be less focussed on bureaucratic processes (Munro 2011). Yet again, the question of identifying practice mechanisms to change the functions of social work practice towards a family support orientation which includes child protection as a core component rather than a sole function has reemerged ( Featherstone, Broadhurst and Holt, 2012)

More specifically, in an Irish context, the recent establishment of the new Child and Family Support Agency (TUSLA) advocates for a greater concentration on prevention and early (in the problem) intervention and on 'better skills fit for purpose and practice' for social workers. A similar policy trend has emerged in the UK in the wake of the 'post Munro' period. Ironically these 'social work policy similarities' between neighbouring countries are purely serendipitous and there has been little description of or comparison between practice trends particularly in relation to family support and child protection. Of course, good policy does not necessarily ensure good practice, and there has also been a dearth of knowledge in understanding what family support means for professionals and families in the Republic of Ireland and the UK and how it is or is not in any way comparable. Thus, it is argued in this paper that some 'reminding and reconfiguring' of core skills for social workers in supporting children and families living in extreme adversity may now be timely in order to compliment emergent policy. This study is a strong indicator that there is value in looking at this from an UK-Irish perspective.

Using a 'twin track' approach, this paper firstly revisits core family support messages for social work practice in working with children and families in the 
light of findings from two high profile cases one in the UK (Munro Review following the case of Baby Peter 2011) and one in the Republic of Ireland (Gibbons Review of the Roscommon Incest Case 2011). Secondly, exploring these identified practice messages through the lens of Family Support Workers testimonies in the UK and Ireland operating in similar services that target hard to engage children and parents, this paper highlights how families and Family Support Worker colleagues in England and Ireland share a common view of the primary- functions of child and family work. It will be argued that by naming a more detailed set of practices considered most useful by families, the messages, the benefits and challenges of intensive family support work has major resonance for social work and multi agency practice into the future.

\section{Common Messages from Similar Failings}

As a result of both the death of 'Baby Peter' due to maltreatment in the UK and the incest by the mother and father of their children as well as severe consistent wilful neglect in what is commonly termed the Roscommon case in Ireland, an outcry against social services generally and social work more particularly ensued. Two major reports were commissioned to identify reasons for this failure and propose lessons for social work policy and practice, the Munro Report (Munro 2011) and Roscommon Report by Gibbons (Government of Ireland 2011), respectively. While in both cases ineffective social work practices were identified either by not responding or by providing poor or inadequate interventions overall, three core issues for social work practice emerged adding weight to the utilisation of family support which includes safeguarding of children. These three common identified issues (which it should be stressed are not the only one's highlighted in both reports) are grouped as follows:

1. The need for direct work with children and families and hearing the voice of the child

2. Developing a strengths based style of working including task completion while ensuring robust monitoring and safeguarding

3. Realistic forms of multi-disciplinary working with other professionals and use of reflective practice skills 
Each of these three factors are now considered in line with the literature and ahead of 'testing' and elaborating on their applicability in the qualitative study central to this paper.

\section{Direct work with children and families and hearing the voice of the child}

There has been much emphasis in both Ireland and the UK on the importance of better assessment of need and risk (Buckley 2006; Horwath 2011). Similarly, there has been a strong push for focusing on better outcomes via proven or promising interventions particularly through manualised robustly evaluated programmes (Axford and Morpeth, 2011). However, it is notable that when one explores the reports into failings by social workers and related professions it is neither of these factors that come to the fore, in that families were often known to the system and may well have been assessed and engaged in interventions at least some extent via a recognised programme. Generally in both Ireland and the UK there has been a waxing of programmatic interventions by professionals other than social workers working with the families. This has been coupled with a waning of direct face to face case work by social workers who have become case managers and now direct 'orchestras of interventions' rather than play any 'lead instruments'. This move away from direct face to face practice was an identified common failing in both the death of Baby Peter Connolly where safeguarding by social workers failed and in the Roscommon Case where Family Support was seen as purely the work of others and not a task for social workers. What is now commonly encouraged is the need for social workers to return to more direct face to face work with children and parents rather than relying on the testimony of other professionals.

This type of weak family support function is not only highlighted by the Munro and Roscommon reports; in the USA more recently Brooks Gunn and colleagues (Martin and Brooks Gunn, 2012) have stressed the connection between strong direct social work support to parents and reduced child maltreatment: this echoes similar calls both in the UK and in Ireland. From a safeguarding 
protective perspective, seeing children and working with them face to face is obvious. Social workers supporting family functioning need to establish a relationship with families (Ferguson, 2011) which in turn, automatically implies social workers have regular face to face contact. The risks of investment in bureaucratic practices by social workers at the cost of less direct work with children and families has been highlighted (Broadhurst et al, 2010). What is somewhat disconcerting is that this information is not new for either child protection/safeguarding system, with high profile cases as far back as the early 1980's where such messages were disseminated but similarly not acted on.

So, social workers listening to and hearing the voice of children through direct work interventions remains crucial. Under the UNCRC Article 12, participation is a fundamental right of the children they work with and for. Furthermore, in terms of child rights based practice by social workers, Bell (2002) has strongly advocated that organic relationship based working is not only a major function of modern day social work but is an obligation for social workers. In terms of supporting looked after children and youth, the importance of social workers working directly with service users is known to be critical in terms of longer term outcomes (Hicks \& Stein 2015).

Ironically, social workers testimonies attest to a strong desire to retain time for direct work (Dolan \& Holt, 2010). Notably, social workers report that the lack of emphasis on direct work is viewed as a loss of the primary reason they entered the profession. Finally here, it could be argued that when one looks at the pioneering work of social workers such as Grace Abbot and her sister in Chicago in the 1930s or Mary Carpenter in Ireland, their work on a day to day basis was in the main direct engagement with children and their families. This was both in their homes and on the street and involved parents - a far from current practice in social work with either such interventions not occurring at all or being seen as less important and the function of other para-professionals.

\section{Strengths based style of working with task completion orientation}


Strengths based working includes instillation of hope for families as a specific task of intervention. Its roots lie in an empathic approach alongside a matched understanding of what children and families actually need. A distinct Style of Working and forming relationships is required which is essentially interpersonal skills that enable workers to connect with families through empathy and human caring; the corner stones of effective relationships (Garbarino, 1992; Whittaker and Garbarino, 1983; Thompson 1995).

From the earlier work of David Saleeby (1992) and others in the US such as Dryfoos (1990) who advocated for 'strengths based working' with children and families, all have highlighted this function in child welfare. This has not been done as an antidote to child protection or denial of the problem of working with complex families but more as an emphasis on an ecological approach to solutions. Recently Brooks Gunn and colleagues (2012) emphasised that family support can apply in child protection work by social workers. Echoing the knowledge created by Gardner in the 2000's, by Thompson in the 1990's and Garbarino and Whittaker in the1980's: all indicated that effective family support with parents can reduce child maltreatment. As Garbarino and Whittaker (1983) have described it: support is the 'bread and butter of relationships': this applies of course not just within families but also between professionals including social workers. Similarly this should not be viewed as occurring only in families who present as compliant with professionals but arguably even more so for those who for whatever reason are highly resistant to interventions.

In social work through strength based working with parents coupled with rigorous adherence to direct work leading to safeguarding children offers the prospect of long term safety and prosperity for children, usually a common desire for parents and professionals alike. However in recent years both in Ireland and UK the erosion of direct work with children by social workers, has been detrimental and ironically, from a review of post graduate education in child protection and social work by Dolan (2002 and 2010) this is due to simply not having enough time to work with families despite the known risks. Whilst the narrowing of the social work role to focus on risk has exacerbated this, individual practitioners arguably have scope to enact 'quiet challenges' to this in 
their day to day practice (Rogowski, 2015). Another aspect of a strengths based approach in the intensive family support models is the need to develop social capital with the families. Social capital is a recognised ingredient in improving outcomes, with workers supporting families to identify individual, family and community strengths (Hawkins and Maurer 2012). However, the ideas of social capital and social support are underdeveloped in social work literature (Geens \& Vandenbroeck, 2014Roose). Similarly, a strengths based approach is crucial, but has been criticised and overlooked as a 'fluffy' or soft approach (Canavan, Pinkerton \& Dolan, 2006). In intensive family support, the use of a strengths based approach has enabled families known to services for a number of years to move forward dramatically (Flint et al, 2011).

\section{Realistic forms of multi-disciplinary working}

Effective multi-disciplinary working for families requires some parity of esteem between professionals. This will be discussed later in the paper in terms of the perceptions of professionals and the family support workers, who can be described as para professionals. Such workers, as will be outlined, with a more intensive involvement and distinctive style of working can achieve different, yet arguably as important, outcomes and contribute to assessment in a tangible way.

In terms of supporting families, the role of the social worker in providing family support is seen as essential by many frontline staff (Devaney 2011) but has been less emphasised by management. Dolan through the development of Ten Family Support Principles (Canavan, Pinkerton \& Dolan, 2006) highlighted the importance of the provision of social support to children and families as a multidisciplinary model for professionals including social workers: "Working in partnership is an integral part of Family Support. Partnership includes, children, families, professionals and communities."

At a most basic level, in order for any social worker to provide such support he or she needs to spend time with families (Dolan \& Holt, 2010). Even in terms of social work practice in difficult child protection cases parents reported the importance of being given time by social workers. Gardner's research (2002) highlights that children and parents were unsatisfied (not getting enough of the 
intervention rather than dissatisfied (not happy with the intervention in the first place) they received from their social worker. So in the first instance the need for social work returning to direct interventions and affording timely and adequate amounts of support to children and families is highlighted along with the importance of relationship building and skill rather than merely increased time (Canavan, Pinkerton \& Dolan, 2006).

In order to frame the findings from our comparative study, in the context of the three factors discussed above, the following graphic illustrates what we regard as tentative suggestions as to how they can be conceptualised for practice in the child and family area. The graphic demonstrates how the 3 areas can be further translated into 7 elements of practice that emerged from our interviews, and their potential implication for direct work which will be returned to later in the paper.

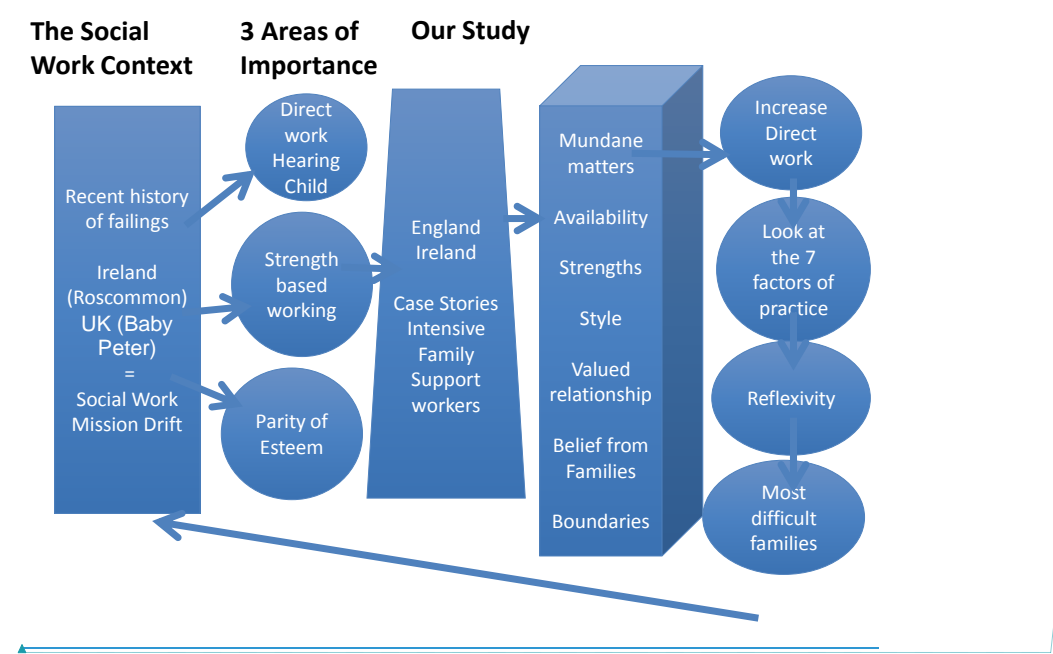

Field Code Changed

\section{Context of the Study}

to provide insight into the workings of the model outlined above, an exploration of practice took place in two separate jurisdictions; the UK and Ireland. For the 
purposes of this qualitative study, intensive family support projects were selected in each area that had several characteristics in common: caseloads included families facing very difficult, multi-faceted and similar problems. In the main, the focus was on learning for practice: examining in fine detail, the strategies at the heart of an intensive family support approach that lead to positive outcomes for children and families when often, all else has failed.

In undertaking this comparative research study, the authors sought to gain a greater understanding of the similarities and differences between individualised practice among family support workers in the UK and Ireland. The focus was on processes, derived from qualitative information gathered in the two neighbouring domains. The rationale underpinning this exploration of family support in practice was to allow a greater understanding of the delivery of such services (Van Puyenbroeck et al 2009). Our task was to examine how the main factors at play in intensive family support yield positive outcomes for children and families. In the UK, the approach has been evaluated extensively less is known, however, about the processes that lead to the success of these intensive interventions.

The primary focus of each of the intensive family support services examined, was to engage hard to reach families, with a particular emphasis on safeguarding children. Both in the UK and Ireland, these intensive family support services had been established to work with the most vulnerable families demonstrating a high level of need. The target population, in both areas, predominantly consisted of very challenging families, known to a number of services over an extended period of time. Initial referrals were frequently characterised by a history of limited engagement or success in the families' interactions with other support services. Both service models adopted almost identical strategies to engage and support families: the allocation of a key worker, interventions located in the home, a strengths-based approach, intensive style of working, relationship based, and in the main, time limited.

\section{Methodology}


This comparative study focused on the self-reported experiences of family support workers in their direct work with children and families. Researchers conducted qualitative interviews with six workers from each agency. The interview consisted of five open ended questions in a semi structured format, eliciting a rich seam of information. From this data, seven themes emerged that were further distilled into those relating specifically to the three headings outlined above. Workers were asked to describe typical tasks, talk about perception of role, organizational structures, internal supports and their hopes for the future of the agency.

In terms of design, the sample was obtained by approaching a FIP team in the nearby Local Authority in the UK, where all of the team members responded positively to the request to take part in the research. Similarly, in Ireland, where the function was contracted by the HSE to an external voluntary service, the manager of the agency was approached- a number of workers came forward to take part, comprising of a self selecting group in this case. The research was conducted with ethical approval; informed consent was sought from participants, verbally and in writing. Efforts have been made, in the presentation of findings, to ensure respondents' anonymity. The authors acknowledge that this study is limited in scale, 12 being a small cohort, and that participants' responses may reflect some intention to match perception of researchers' expectations. However, the authors are confident that the lengthy and detailed responses, containing a wealth of practice examples, indicated that the participants openly expressed their experiences of practice in this area.

\section{Findings}

From each set of interviews in the two locations, seven key themes emerged. In fact, almost identical issues were raised during the course of the interviews in each jurisdiction. These themes are set out below and are grouped into three main overarching areas, corresponding to the discussion threads in this paper. 


\section{The Need for direct work with children and families and hearing the voice of the child}

The issue of direct work emerged as a key area in the two sets of interviews. Clearly a central theme in child and family services generally, the responses could be grouped here into three sub sections as below.

\section{Mundane tasks}

Firstly, the great variety and scope of work carried out by the workers was evident in the rich accounts of practice examples and tasks carried out by the workers. A number of the tasks outlined could be described as quite mundane, everyday activities such as routine domestic chores. However, these appeared to be practical activities that were both valued and vital to the functioning of the families. Alongside these practical tasks was the involvement in communication and emotional issues that arose as a matter of course within the families, for example conflicts between parents and adolescents. Although such interventions appear quite routine and trivial in themselves, they are clearly issues that can severely impair the day to day interactions of a family who are struggling with multiple challenges. What was particularly noteworthy was the level of skill displayed by the workers who appeared to simultaneously carry out practical, emotional, assessment and developmental tasks with family members. In both the UK group and Irish cohort featured respectively below, it was reported that tasks might include:

“...direct work, going shopping ...cleaning...wishes \& feelings work with children, safety plan with children ...debt work, court reports...it's so varied really..."

Within these examples, direct work that emphasised the voice of the child and the family was evident. The workers clearly adapted their range of tasks according to the wishes and needs of the family members, showing a child centred and service user focussed approach.

\section{Relationships count}


The issue of relationship building emerged across both sets of interviews. Citing examples of their relationship building, FIP workers from the UK and then their Irish counterparts noted:

$$
\text { “...you really get in there..." }
$$

'You have to gain a person's confidence and then other things might start coming out.'

Linked to this issue is the inability of more traditional statutory services to achieve this level of engagement, in part due to a service emphasis on considerably more time spent with families in this model. As has been noted, this aspect of intensive family support work appears key to the outcomes that are achieved. Recent inquiry reports, discussed earlier, have indeed highlighted the lack of time spent in forming relationships and the associated negative impact on assessment and intervention with families. Thus indicating the pivotal role of this level of engagement Both the UK and Irish workers respectively, refered to the in-depth and relationship based nature of the work:

"...issues that the social worker thought were there...are not as bad..."

'They might tell you things that they don't tell other service providers.'

\section{Perceived availability of workers -a basic but key issue}

As can be seen from the responses, the intensity of the work and the focus on relationship building were central for workers and also for the families themselves. There was evidence in the workers' responses that families had a real sense that the FIP workers were available to meet their needs on a flexible basis. This notion of a needs led service provision rather than service led has been advocated by a number of commentators. In the UK and Irish samples respectively, participants commented on their perceived availability to families:

“..that I can be approached..that I'm there 24/7...'

'You're going into their houses so much that you become part of the furniture' 
Being considered to be approachable when the family or child might require them appears to be an important characteristic of direct family work. In contrast to service user perceptions of more 'traditional' services including social work, the concept of availability is strong.

\section{Developing a strengths based style of working with task completion orientation, ensuring robust monitoring and safeguarding}

In this intensive family support role, it is apparent from the responses that worker approach was very much strengths based. The examples showed a sense of the workers seeing hope and the prospect for change in these difficult cases.

\section{Small steps- incremental resilience building}

A strengths based perspective focuses on the idea that resilience can be built by working towards and acknowledging small improvements or steps forward. These ideas are very much linked to the concept of empowerment which can develop sustainable change and growth in families. Rather than a focus on difficulties or lack of progress, the approach seeks to promote positive change on a step by step basis and at a pace that is appropriate for each family. To achieve overall change, workers sought to encourage small amounts of progress in the knowledge that this could lead to the resolution of overall problems on an incremental basis. Spending time with families also meant that workers 'captured' small but significant turning points or improvements. Comments from the workers in the UK and Irish groups respectively were:

“..small changes over time...”

'When we go in and we start to do the small things with them, it gives them hope.'

\section{Strengths perspective -style of working}

Style of working, from a strengths based perspective appeared to be intrinsic to the intervention of the FIP workers. There was a real sense of a very definite and well-articulated approach from the family support workers. In the interviews 
they readily described a person centred approach to their engagement. They were clear that this was a very distinctive approach: a style of working that they were purposefully undertaking. Confidence was expressed, as in the above sample of quotations that this was a successful style of intervention and was a fitting approach to utilise with the complex families that they dealt with. Reflecting this clear and confident sense of a style, the UK and Irish group respectively reported:

\footnotetext{
“...it's like old fashioned social work...”

“...you see a glimmer of hope...you have to contradict the social worker...”
}

\section{Realistic forms of multi-disciplinary working with other professionals and utilising reflective practice skills}

Another set of issues raised was around the fact that the workers readily adopted a key worker role, viewing their input with families as quite pivotal. Some workers referred to themselves as the 'lead professional.' However, workers had a sense that their role was not understood and viewed positively by all professionals; particularly social workers.

This issue was raised by both sets of family support workers and was a feature of all the interviews. Whilst the workers appeared to display a high level of confidence in their ability and the outcomes they facilitated, there was a real sense that this was not reflected by others. All the workers were conscious of their status in relation to other professionals, although they did in fact have a variety of qualifications and work experience. Social workers in particular were mentioned as not being appreciative of both the importance of the workers role and the significance of the seemingly 'menial' tasks undertaken with families. Both the UK and Irish groups respectively, expressed the view that:

“...I wish other professionals recognised our role more...”

'Social Workers don't have the same insight.' (would we put this quote earlier?) 


\section{Working together, professional practice \& boundaries}

Alongside the issues of working with other professionals, the setting and maintaining of boundaries was raised by all workers. Due to the intense nature of the input provided and the amount of time spent with each family, the workers felt that maintaining appropriate professional boundaries was an important element.

Family Support Workers in both the UK and Ireland described how this evolves: feeling like "...part of the family..."

"It becomes acceptable that we just come in and we can roam through the house." In relation to this, the Irish workers in particular, mentioned the need for robust and reliable supervision systems. The importance of reflective supervision in order to maintain appropriate boundaries is a recognized feature of professional practice. This element is a priority in terms of service responsibility to support staff who frequently work intensively, often out of hours with some of the most complex and challenging families.

\section{Discussion}

The three key factors outlined in the introduction of this paper are analysed with reference to our research results below. By interviewing the practitioners about their role with families, the aim was to shed light on their applicability and propose tentative messages for practice for child \& family professionals. The Intensive Family Support projects in each jurisdiction targeted families that in policy terms have become known as 'hard to reach' by services; also having what is categorised as high need, typically corresponding to level 4 on Hardiker, Barkers \& Exon'sHierarchy of Need Model (1991). In both cases, recognition by government of the shortcomings of traditional, formal practice, had led to additional provision being funded that would be flexible and relationshipcentred and ultimately more cost-effective in its approach to work with vulnerable children and families (Munro 2011). Each service had developed a style of working that responded to the needs of the family rather than there being an expectation placed on the family to fit into the service. In order to achieve this, the services operated predominantly in the home, effectively 
'wrapping around' the family. Interventions were designed to support the family as a whole, working with children and parents both separately and as a unit.

\section{Relationships and Direct Work}

Creating a relationship of trust led to families accepting the support offered and opening up to discuss more sensitive matters that got to the heart of the family's difficulties, often signalling a' turning point' in terms of enhancing the family's resilience.

Workers recognised that this opportunity to observe family functioning could also provide an alternative perspective on the initial reason for the referral. Frequently, workers became aware that the primary issue they had been asked to address with the family was a symptom not the root cause of the problem. For example, a worker might conclude that a family struggling to establish order and discipline for their children had been referred initially for poor school attendance. Ensuring that children attended school regularly without addressing these underlying issues would only yield short term benefits and satisfied a professional agenda rather than improving the family's quality of life. In a similar case, a family was referred for poor attendance and participation in school. When the worker visited the home, she found that basic home management and lack of hygiene required attention in the first instance. As the children became more familiar and trusting they confided that they were reluctant to go to school as they had experienced social isolation due to their poor hygiene. Again, addressing these underlying factors, removed some of the barriers for the children. School attendance and participation subsequently improved, increasing the probability of this outcome being maintained in the long term. This emphasis on working with both children directly (O'Reilly \& Dolan, 2016) and with parents was found to provide an unambiguous focus on safeguarding, with the concerns of professionals made explicit to the family.

Establishing a rapport and starting from a strengths-based perspective was deemed paramount in each jurisdiction. The agencies interviewed indicated that the relationship between worker and family was the most essential component of the intervention. The key worker approach meant that stime could be spent to 
build relationships of trust. This key worker was expected to work intensively with the family, be available beyond the rigid confines of State provided services in terms of hours and location, tailoring service provision to suit the requirements, pace and expressed needs of the family, (Hardy and Darlington 2008). The benefits of this approach by workers chime with recent literature analysing the UK FIP projects (Flint et al, 2011). Although, in its principles social work advocates a democratic partnership approach with families, in child welfare practice this arguably becomes a reductionist form of partnership (Roose et al, 2013): the more democratic relational approach is a feature of the examples from our study.

Central to this approach to intensive family support work is the breadth of activities undertaken. This was highlighted as an important, often essential, element of the success experienced with a family. Direct work with families encompassed a wide variety of tasks, including the four elements of social support (practical, emotional, advice and esteem), as identified by Cutrona (2000). All spoke about the spectrum of roles adopted with a family in one week, ranging from painting rooms to parenting support to attending court hearings to family outings. Priorities were established with the family by examining the most urgent concern and factoring other issues into a family plan as time went on. The initial referral in the majority of cases had been from Social Work and was a child protection or welfare concern. Significantly, it was through this range of support, particularly around practical and emotional support, that relationships with the child and family were strengthened. Each service had developed a style of working that responded to the particular set of needs of the family. The value of the relationship in itself as a key feature of intervention is highlighted by others (Mc Keown,2013). Sandau-Beckler et al (2002) argues that the client relationship is the most active ingredient of change in child protection.

\section{Strengths Based}

A strengths based approach was central to both models , reflecting an increasing interest in both social work (Weick, 2009) and related fields. Having regular access to the family in their own home environment gave workers an insight into 
the unique strengths and challenges in each case. Interestingly, workers spoke about the opportunity this opened up to observe small positive changes that might otherwise be missed. One worker spoke about a family that had been referred due to concerns about the parent's capacity to organize routines, largely due to a learning disability. The worker observed that one of the children received her prescribed medication very sporadically at the start of the intervention. Within weeks, with regular and consistent guidance, a routine had been established and lapses became increasingly rare. This indicated to the worker that, with support, this parent was capable of implementing routines and she began working with the parent and children to establish childcare and household management systems in the home. In contrast, other agencies had spoken to the parent about the short-comings they observed in her children's care but had neglected to work with 'mom' to identify practical solutions. This led to feelings of 'hopelessness' and both mother and professional agencies shared a united perception of failure. The family support worker, in this case, spoke about 'instilling hope' and 'inspiring confidence' and commented that these small steps had become a powerful catalyst leading to significant positive changes in other aspects of the children's care.

The policy within both agencies was to discuss the reason for referral prior to the intervention commencing and in line with best practice ensure that the voice of the child was heard. An initial consultation with children and then parents informed the subsequent family plan. This led to families having a full understanding and 'buy in' vis a vis a shared expectation of the desired outcomes. This 'up front' approach ensured that safeguarding issues were to the forefront of this strengths based approach.

It has been suggested that taking a strengths based approach requires a change of orientation by workers (Blundo, 2001), conceptualising the professional or paraprofessional as 'doing with' rather than 'doing for'. Similarly Roose et al (2014) suggest the aspiration to implement a strengths based and relational approach in practice is not an easy challenge in child welfare settings. Lietz (2011) found in an empirical study that families perceptions of a strengths based approach did not always match the workers reported use of this. Arguably, as 
Rapp et al (2005) point out, the growing popularity and talk within social work about taking a more strengths based approach has not translated into practice In contrast, for this group of para- professionals it remained central.

\section{Multi agency working}

It was noted that the often very practical aspect of the work is fundamental to the successful outcomes of such interventions. However, the family support workers felt that while this could be regarded as mundane it was crucial to the daily lives of families, but could be overlooked by other professionals. Flexibility is maintained by the agencies' recruitment criteria; drawing on a broad base of skills and expertise in the area of child and family support work. This expansive pool and the relationship based approach were identified as strengths by each of the workers interviewed but also as potential barriers when interacting with state agencies, as the on-going debate about the professionalization of Family Support continues (Dolan \& Holt, 2010). Workers spoke about the chronic level of difficulty some families experience and the need for a long term, co-ordinated multi-disciplinary response for families experiencing most adversity. However, parity of esteem with decision makers such as Social Workers was reported as variable in quality, and frequently determined on an individual personality driven basis.

Given the personal, up-close nature of the work, maintaining boundaries was cited as an area requiring sensitivity and external support. Supervision was, in all cases provided to workers and flagged as imperative for this type of intensive face to face case work. Other studies however have shown that workers with high levels of stress and high caseloads can still effectively implement a strengths based approach in their work (Kemp et al, 2014). Both agencies had been affected by budgetary cuts due to the recession in the UK and Ireland, impacting on recruitment, resources available to families, staff stress levels, training and development. A crucial issue remains for family support both as a style of working and a set of services going forward: in an age of austerity, this possibly remains one of its key challenges. 


\section{Conclusion}

A basic message from this study is that invaluable lessons in engagement and intervention with families can be drawn for professionals by examining the practice elements of this group of para professionals in the child and family arena.

The authors suggest that whilst these findings relate to the particular context of intensive family support projects, their applicability to social work and other professionals in the child and family arena is obvious. Although the amount of time spent by key workers is undoubtedly a factor in the success of the interventions, it is the elements of practice themselves that we have sought to examine, as key ingredients of successful practice with families. Returning to the tentative 'formula for practice' outlined in the graphic earlier, the elements of practice identified can be reflexively and thoughtfully applied to the most difficult families by a range of professionals if the benefits of these factors are recognised.

The focus on early intervention - intervening intensively with 'trouble some' families has become a government priority in both Ireland, the UK and beyond (Featherstone, White and Morris, 2014), developing even further since our study with the advent of the Troubled Families agenda in the UK and the national rollout of Meitheal in Ireland (a discussion of which goes beyond the scope of this paper)

This paper is a reminder of the merits of promoting a relational and strengths based approach when working with vulnerable and complex families for social work and other professionals as well as family support. For social work, revisiting and embracing these ideas and the practice factors identified could provide a timely focus. Recent debate in the social work field bemoans the shift towards a reduction of direct working and a narrower focus on child protection. 
The findings from this study indicate that a return to a more relationship orientation will ensure that the contribution that social work makes can be strengthened. Perhaps within the current narrower remit in both jurisdictions, child \& family social work can still firmly retain its value base by drawing on the fundamental family support theory and practice principles.

\section{References}

Axford \& Morpeth, 2011. Evidence-based programs in children's services: A critical appraisal. In Children and Youth Services Review. Vol 35, Issue 2, February 2013, Pp268-277

Bell, M. (2002) Promoting children's rights through the use of relationship, Child and family social work, 7(1): 1-11

Blundo R, 2001. Learning strengths-based practice: Challenging our personal and professional frames. Families in Society, 82 (3) (2001), pp. 296-304

Broadhurst K, Hall C, Wastell D, White S \& Pithouse A, 2010. Risk, Instrumentalism and the Humane Project in Social Work: Identifying the Informal Logics of Risk Management in Children's Statutory Services. British Journal Social Work (2010) 40 (4): 1046-1064

Buckley H, Basarab-Horwath J, Whelan S, 2006. Framework for the Assessment of Vulnerable Children and Their Families: Assessment Tool and Practice Guidance. Publisher Children's Research Centre, Trinity College, 2006, Dublin

Canavan, J., Pinkerton, J. and Dolan, P. (Eds.) (2006) Family Support as Reflective Practice, London: Jessica Kingsley

Cutrona C, 2000 Social Support Principles for Strengthening Families: Messages from the US in (eds) J. Canavan, P.Dolan \& J. Pinkerton Family Support: Directions from Diversity London: Jessica Kingsley, pp103-122 
Devaney, C (2011) Family Support as an Approach to Working with Children and Families. An Explorative Study of Past and Present Perspectives among Pioneers and Practitioners. Germany: LAP LAMBERT Academic Publishing.

Dolan, P (2002), What Families Want in Family Support: An Irish Case Study. Child Care in Practice, Vol. 8, No. 4, 2002.

Dolan P and Holt, S. (2010) Great Expectations: The Tension Between what Service Users Need and what Practitioners Can Deliver. Administration, Vol. 58, No. 2, pp. 99-123.

Dryfoos, J. G. (1990). Adolescents at risk: Prevalence and prevention. New York: Oxford University Press.

Featherstone B, Broadhurst K \& Holt K, 2012. Thinking Systemically-Thinking Politically: Building Strong Partnerships with Children and Families in the Context of Rising Inequality. British Journal of Social Work (2012) 42 (4): 618-633

Featherstone B, White S \& Morris K, 2014. Reimaging Child Protection. Policy Press

Ferguson, H, 2011. Child Protection Practice. Houndmills: Palgrave Macmillan

Flint, J., Batty, E., Parr, S., Platts-Fowler, D., Nixon, J. and Sanderson, D. (2011) Evaluation of Intensive Intervention Projects. London: DfE

Frost, N and Dolan, P(2012) 'The Theoretical Foundations of Family Support Work', in Davies, M. (ed.) Social Work with Children and Families, Palgrave Macmillan, pp. 40-49.

Garbarino J, 1992. Children and Families in the Social Environment. Walter de Gryuter: NY

Gardner R, 2002. Supporting Families: Child Protection in the Community. Wiley \& sons, Chichester

Geens, N., \& Vandenbroeck, M. (2014). The (ab) sense of a concept of social support in parenting research: a social work perspective. Child \& Family Social 
Work, 19(4), 491-500. Gibbons, N, 2011. Roscommon Child Care Case. Report of the Inquiry Team to the Health Service Executive.

Hardiker, P., Exton K. And Barker, M. (1991) Policies and Practices in Preventive Child Care. Avebury, Aldershot.rch 2010 9: 93-109

Hardy, F. \& Darlington, Y. (2008). What parents value from formal support services in the context of identified child abuse. Child and Family Social Work, 13, 252-261

Hawkins, R. L. \& Maurer, K. (2012). Unravelling social capital: Disentangling a concept for Social Work. British Journal of Social Work, 42(2), 353 - 370.

Hicks L \& Stein M, 2015. Understanding and working with adolescent neglect: perspectives from research, young people and professionals. In Child \& Family Social Work. Vol 20(2), pp.223-233

Horwath, J. (2011) 'See the Practitioner, See the Child: The Framework for the Assessment of Children in Need and their Families Ten Years On' in British Journal of Social Work. Vol 10.1093

Jack, G, 1997. 'Discourses of Child Protection and Child Welfare'. In British Journal of Social Work Vol: 27 (5): 659-678flintKemp, S. P., Marcenko, M. O., Lyons, S. J., \& Kruzich, J. M. (2014). Strength-based practice and parental engagement in child welfare services: An empirical examination. Children and Youth Services Review, 47, 27-35.

Lietz, C. A. (2011). Theoretical adherence to family centered practice: Are strengths-based principles illustrated in families' descriptions of child welfare services?. Children and Youth Services Review, 33(6), 888-893.

Martin, A., Gardner, M. and Brooks-Gunn, J., 2012. The mediated and moderated effects of family support on child maltreatment. Journal of family issues, 33(7), pp.920-941

Mc keown K, 2013 'Using Evidence to Develop Services for Children and Families' Administration, Volume 61, No 1, April 2013. 
Munro E, 2011. Munro review of child protection: final report - a child-centred system. HM Government London, The Stationary Office

O'Reilly, L., \& Dolan, P. (2016). 'The Voice of the Child in Social Work Assessments: Age-Appropriate Communication with Children'. British Journal of Social Work, 46(5), pp.1191-1207.

Rogowski, S. (2015). Margaret Thatcher's legacy for social work with children and families: critical possibilities?. Critical and Radical Social Work, 3(1), 53-65.

Roose, R., Roets, G., Van Houte, S., Vandenhole, W., \& Reynaert, D. (2013). From parental engagement to the engagement of social work services: discussing reductionist and democratic forms of partnership with families. Child \& Family Social Work, 18(4), 449-457.

Roose, R., Roets, G., \& Schiettecat, T. (2014). Implementing a strengths perspective in child welfare and protection: A challenge not to be taken lightly. European Journal of Social Work, 17(1), 3-17.

Saleeby, D 1992. The strengths perspective in social work practice. New York: Longman.

Sandau-Beckler, P., Salcido, R., Beckler, M. J., Mannes, M., \& Beck, M. (2002). Infusing family-centered values into child protection practice. Children and Youth Services Review, 24(9-10), 719-741.

Thompson N, 1995. Theory and Practice in Human Services. OU Press

Puyenbroeck, H. V., Loots, G., Grietens, H., Jacquet, W., Vanderfaeillie, J. and Escudero, V. (2009), Intensive family preservation services in Flanders: an outcome study. Child \& Family Social Work, 14: 222-232.

Rapp, C A, Saleebey D \& Sullivan P, 2005. The future of strengths-based social work. Advances in Social Work, 6 (1) (2005), pp. 79-90

Weick, A. (2009). Issues in overturning a medical model of social work practice. Reflections, /5(3), 7-1 
Whittaker J \& Garbarino J, 1983. Social Support Networks: Informal Helping in the Human Services. Aldine de Gruyter: NY 